\title{
Perspectivas territoriais de desenvolvimento a partir do Turismo Rural: o caso do território Quarta Colônia/RS, Brasil
}

\author{
Caroline Ciliane Ceretta \\ Universidade Federal de Pelotas - Pelotas - RS - Brasil \\ ORCID: https://orcid.org/0000-0002-5071-0321 \\ Dalva Maria Righi Dotto \\ Universidade Federal de Santa Maria - Santa Maria - RS - Brasil \\ ORCID: https://orcid.org/0000-0002-0374-4430 \\ Mônica Elisa Dias Pons \\ Universidade Federal de Santa Maria - Santa Maria - RS - Brasil \\ ORCID: http://orcid.org/0000-0002-0935-0168 \\ Greicy Sofia Maysonnave \\ Universidade Federal de Santa Maria - Santa Maria - RS - Brasil \\ ORCID: http://orcid.org/0000-0003-3722-0886
}

\begin{abstract}
Resumo
Na perspectiva territorial de desenvolvimento, o território da Quarta Colônia de imigração italiana, situado no centro do Estado do Rio Grande do Sul / Brasil, vem investindo na atividade turística para alavancar seu desenvolvimento em consonância com outras atividades produtivas. Como estratégia, o turismo tem sido acionado para compor as narrativas de comercialização e divulgação dos recursos naturais e culturais específicos encontrados no próprio território. Apesar do incentivo público no desenvolvimento da atividade, a criação de rotas e roteiros turísticos não atendeu as expectativas dos empreendedores locais. Neste aspecto, o objetivo principal foi analisar os aspectos que inibiram o processo de desenvolvimento do turismo no território. Metodologicamente, o estudo tem o corte qualitativo e a coleta de informações se deu por meio de fontes primarias e secundárias. Como resultado, o estudo apontou que apesar do apoio governamental, os atores locais não foram inseridos no processo de desenvolvimento do turismo e a fragilidade do capital social impediu que muitas atividades turísticas obtivessem êxito ao longo dos anos. Contudo, o turismo tem retomado seu processo de crescimento impulsionado pelos atores locais que de forma conjunta, preparam e ao mesmo tempo,
\end{abstract}


vivenciam atividades recreativas, trilhas e caminhos rurais, festejos e eventos gastronômicos.

Palavras-chave: Desenvolvimento. Território. Atrativos Turísticos. Turismo Rural.

\title{
Territorial perspectives of development from Rural Tourism: the case of the territory Quarta Colônia / RS, Brazil
}

\begin{abstract}
From the territorial perspective of development, in the territory of the Fourth Colony of Italian immigration, located in the center of the state of Rio Grande do Sul / Brazil has been investing in tourism to leverage its development in line with other productive activities. As a strategy, tourism has been used to compose the commercialization and dissemination narratives of the specific natural and cultural resources found in the territory itself. Despite the public incentive to develop the activity, the creation of tourist routes and itineraries did not meet the expectations of local entrepreneurs. In this aspect, the main objective was to analyze the aspects that inhibited the process of tourism development in the territory. Methodologically, the study has a qualitative cut and the information was collected through primary and secondary sources. As a result, the study found that despite government support, local actors were not included in the tourism development process and the fragility of social capital prevented many tourism activities from succeeding over the years. However, tourism has resumed its growth process driven by local actors who jointly prepare and at the same time experience recreational activities, rural trails and paths, festivities and gastronomic events.
\end{abstract}

Keywords: Development. Territory. Tourist attractions. Rural Tourism.

\section{Perspectivas territoriales del desarrollo del turismo rural: el caso del territorio Quarta Colônia / RS, Brasil}

\section{Resumen}

Desde la perspectiva territorial del desarrollo, en el territorio de la Cuarta Colonia de inmigración italiana, ubicada en el centro del estado de Rio Grande do Sul / Brasil, ha estado invirtiendo en turismo para aprovechar su desarrollo en línea con otras actividades productivas. Como estrategia, el turismo se ha utilizado para componer las narrativas de comercialización y difusión de los recursos naturales y culturales específicos que se encuentran en el propio territorio. A pesar del incentivo público para desarrollar la actividad, la creación de rutas e itinerarios turísticos no cumplió con las expectativas de los empresarios locales. En este aspecto, el objetivo principal era analizar los aspectos que inhibían el proceso de desarrollo turístico en el territorio. Metodológicamente, el estudio tiene un corte cualitativo y la información se recopiló a través de fuentes primarias y secundarias. Como resultado, el estudio encontró que a pesar del apoyo del gobierno, los actores locales no fueron incluidos en el proceso de desarrollo turístico y la fragilidad del capital social impidió que muchas actividades turísticas tuvieran éxito a lo largo de los años. Sin embargo, el turismo ha reanudado su proceso de crecimiento impulsado por actores locales que preparan conjuntamente y al mismo tiempo experimentan actividades recreativas, senderos y caminos rurales, festividades y eventos gastronómicos.

Palabras clave: Desarrollo. Territorio Atracciones turisticas. Fragilidad.

\section{Introdução}


Com o enfraquecimento do sistema produtivo colonial policultor da Quarta Colônia de imigração italiana no centro do Estado do Rio Grande do Sul, acelerado pela modernização da agricultura entre os anos de 1950 e 1970, os municípios que compõem o atual território enfrentaram um período de êxodo rural, de crises políticas que perdurou até meados da década de 1990. Desde então, as mudanças socioeconômicas revelam estratégias de desenvolvimento sustentável articulados de forma integrada para os pequenos municípios rurais (FROEHLICH; VENDRUSCOLO, 2012).

Entre as atividades pensadas para dar visibilidade ao território e aumentar a circulação e comercialização de produtos locais, a atividade de turismo passou a integrar as narrativas políticas de valorização dos recursos naturais e culturais para a divulgação dos produtos identitários da Quarta Colônia.

No entanto, ao mesmo tempo em que o turismo foi uma das apostas pensadas como estratégia para alavancar o desenvolvimento sustentável do território, as propostas rumaram atualmente para outras estratégias surgidas entre os moradores locais. O expressivo conjunto de atrativos culturais em torno da herança étnica, o cenário rural bucólico aflorado entre os rebordos do Planalto e a depressão central do estado, bem como o conteúdo étnico cultural predominante da colonização italiana permitiram que diversas rotas e roteiros turísticos fossem elaboradas para a comercialização dos produtos turísticos identitários, constituindo uma oferta turística politicamente estruturada.

Apesar da divulgação da atividade turística circular em diversos veículos midiatizados e o incentivo por parte das governanças locais ter dado base aos projetos de turismo em torno de uma proposta integrada e sustentável, além da presença de visitantes circulando entre os municípios, a proposta em torno dos roteiros turísticos não conseguiram êxito, e se quer foram comercializados (SILVEIRA et al., 2012).

Diante de tais aspectos, este estudo tem como objetivo geral analisar os principais fatores que inibiram o processo de desenvolvimento sustentável do turismo no território e em especial apresentar os principais elementos identitários acionados para incentivar a prática de turismo no território; compreender os aspectos utilizados junto a perspectiva territorial de desenvolvimento e sua relação com os recursos locais específicos, bem como os novos produtos e serviços turísticos que surgiram diante de uma proposta territorial de desenvolvimento.

Metodologicamente, o estudo caracteriza-se com o caráter qualitativo de investigação, reunindo aspectos exploratórios e descritivos para apresentar o referencial teórico e a coleta de informações bibliográficas e empírica (TRIVIÑOS, 2011). O estudo de caso caracteriza-se pela investigação da Quarta Colônia (Figura 1) enquanto território construído socialmente por seus atores (BERGER; LUCKMANN, 2014). O instrumento para coleta de informações primárias foi a entrevista semiestruturada junto aos atores locais, tanto representantes políticos como moradores. Para análise dos resultados, utilizou-se analises-descritivas. 
Figura 1. Mapa de localização dos municípios da Quarta Colônia/RS

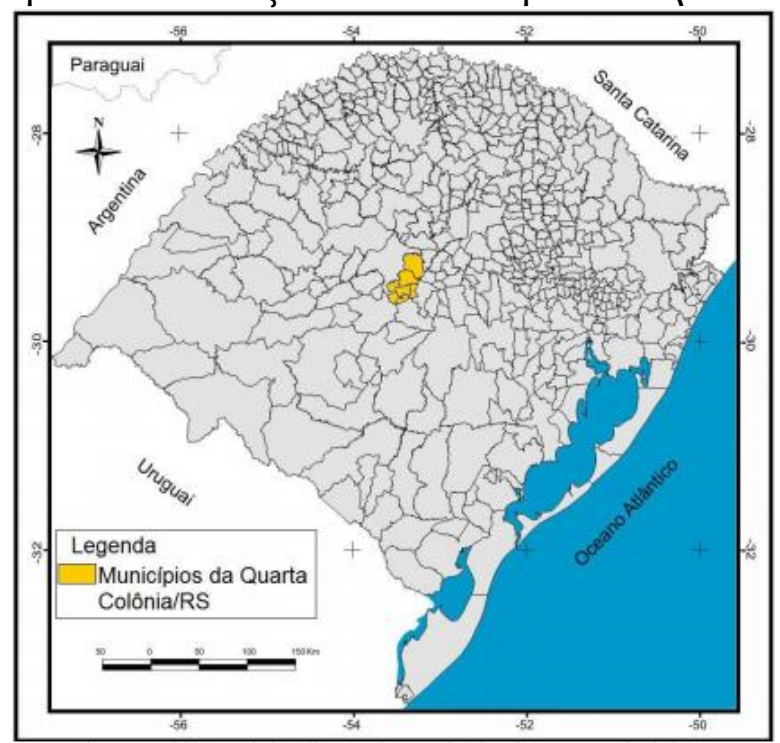

Fonte: Dados IBGE (2010), adaptado por Manfio et al. (2017)

Dessa forma, o estudo apresentado é formado por dois eixos teóricos e analíticos, os quais complementam-se para inicialmente trazer breves notas sobre a concepção do desenvolvimento territorial, incentivada como nova dinâmica pensada em torno da dinâmica local de desenvolvimento (PECQUEUR, 2005; CAZELLA, 2012). O segundo eixo mostra no conjunto teórico-prático o estudo de caso e os resultados da investigação junto ao território Quarta Colônia. Por fim serão apresentadas as conclusões alcançadas e as referências bibliográficas que embasaram a investigação.

\section{Breves notas sobre a perspectiva territorial de desenvolvimento}

As mudanças nos processos agrários e agrícolas mundiais que marcaram o século XX evoluíram, após a crise dos anos de 1970, para uma nova proposta em torno do desenvolvimento econômico das nações capitalistas, principalmente nos países de economia emergente. O enfoque territorial verificado entre os distritos industriais italianos e as 'pays' francesas provocariam novas ações em torno do desenvolvimento e sua concepção econômica predominante (CAZELLA, 2012).

Na década de 1980, o rural passou a ser palco de oportunidades agrícolas e não agrícolas, decorrente das estratégias para diversificar a economia produtiva, descentralizar políticas e permitir que outras dinâmicas sociais, culturais e ambientais pudessem ser visualizadas junto as iniciativas de desenvolvimento.

Quando a União Europeia lançou o Programa Ligações entre Ações do Desenvolvimento da Economia Rural (Leader) em 1991, a intenção era dinamizar os espaços rurais a partir do financiamento de projetos inovadores elaborados por atores públicos e privados de países em desenvolvimento, numa abordagem ascendente para melhor aproveitamento dos conhecimentos tradicionais, da valorização do patrimônio local e da qualidade de vida às populações rurais. Era o nascimento de uma nova perspectiva em torno do território e suas dinâmicas para o enfrentamento das crises que atingiam o cenário rural e consequentemente 0 
urbano. Surge a concepção de desenvolvimento sob o ângulo territorial, o qual vincularia o espaço físico e seu conteúdo social ao ápice da mudança (VEIGA, 2001; CAZELLA, 2012).

Nos países considerados subdesenvolvidos, a exemplo da América Latina e África, os organismos internacionais, como o Banco Mundial e o Instituto Interamericano de Cooperação para Agricultura (IICA) passaram a valorizar a abordagem territorial do desenvolvimento na perspectiva de encontrar atributos nos próprios territórios, como medida para a descentralização política de decisões e planos de desenvolvimento locais (CAZELLA, 2012).

A nova percepção sobre o meio rural e suas atividades produtivas trouxe 0 reconhecimento da heterogeneidade dos espaços, sua capacidade endógena de se desenvolver, e projetar outras atividades para além do uso exclusivo agrícola. $O$ rural passou a ser reconhecido como parte de um território de construção social, formado por entidades, atividades produtivas, recursos naturais e todo o conteúdo cultural identitário de seus atores (CAZELLA; BURIGO, 2008). Nesse contexto, alguns aspectos foram essenciais para a nova perspectiva em torno do desenvolvimento sustentável, tais como a valorização e o fortalecimento da agricultura familiar, a diversidade das economias dos territórios, o estímulo ao empreendedorismo local e o apoio governamental (VEIGA, 2001).

Para Schneider (2004) e Abramovay (2002) a abordagem territorial é resultado de uma descentralização de políticas públicas e de uma maior valorização dos atores sociais na participação das decisões locais, onde o território passou a ser a nova unidade de referência para o Estado e as ações de intervenção decorrentes deste deslocamento passaram a denominar-se desenvolvimento territorial.

Nesse sentido, a gastronomia, o turismo cultural, a agricultura familiar, as Indicações Geográficas e outros fatores correlacionados passam a ter grandes chances de serem reconhecidos como parte estratégica para acionar o desenvolvimento. Todavia na perspectiva territorial, isso só é possível se os recursos naturais e culturais encontrados no território passam a ser reconhecidos por eles mesmo para constituir valor de uso junto ao território (PECQUEUR, 2005). Os processos de ativação dos recursos locais específicos encontrados nos territórios são fundamentais para desencadear novas redes políticas e estruturais para conduzir o processo e acompanhar o desempenho dos projetos entre os atores locais. Estes projetos estarão atrelados ao valor social construído por seus atores mediante o reconhecimento de tais recursos revelados no próprio território, isto é, identitários.

Nas representações sociais manifestadas em meio a interação social é que o território assume sua identidade construída. Identidade essa expressada pelo patrimônio cultural comum, de grupo e que através do modo de ser, pensar, agir e falar gera representações simbólicas. Para Froehlich e Vendruscolo (2012), a perspectiva antropológica da identidade expressa o sentimento de pertencimento de um grupo que compartilha símbolos e significados, delimitadas por saber-fazer local historicamente constituído. Da mesma forma, Silveira et al. (2012) aponta que a identidade se constitui de subjetividades individuais e coletivas, as quais podem estar relacionadas a especificidades históricas de determinados grupos sociais ou ao sentimento de pertencimento territorial. 
A referência à descoberta de "ativos" gerados a partir de recursos culturais mobilizados por seus atores é premissa na valorização do tecido social e produtivo do grupo, pois só será possível reconhecer as novas dinâmicas e oportunidades do território se os atores sociais do próprio local reivindicar sua identidade cultural seja ele material ou imaterial para criar territorialidades.

Por isso, Pecqueur (2005) revela que os ativos são fatores em atividades cujo valor depende das condições de seu uso e resultam dos recursos diferenciados e específicos encontrados. Sua natureza complementar junto aos aspectos econômicos produtivos permite visualizar hábitos, saberes, expressões linguísticas, símbolos e outros aspectos culturais, como elementos fundamentais que dispostos em proximidade ou comunidades que quando estimulados podem revelar sua identidade e distintividade perante si e demais territórios. Assim, os recursos específicos identificados no território são transformados em ativos quando identificados e valorizados pelos atores sociais internos e externos ao processo, 0 que revelaria a concepção de desenvolvimento territorial.

Como a identidade de um grupo é socialmente construída a partir de determinados elementos culturais, tomados como referência em relação a outros grupos, os valores culturais específicos serão catalizados pela variável territorial para agir como mobilizadora de novas territorialidades (ABRAMOVAY, 2002). Neste cenário, o desenvolvimento territorial passa a ser um conjunto de mobilizações dos atores que desencadeia uma estratégia de adaptação aos limites externos, a partir de uma base de identificação coletiva com uma cultura e um território. Assim, o desenvolvimento territorial não pode ser implantado por decreto e é dependente de uma construção de atores locais, mesmo que existam políticas públicas capazes de estimular e mobilizar externamente. Ademais, a dimensão do tempo é fundamental para que a construção social aconteça junto aos territórios (PECQUEUR, 2005).

Na perspectiva do desenvolvimento local e regional, segundo Becker (2002, p. 55) "a competitividade e, portanto o desenvolvimento de uma determinada região passa pelo necessário esforço doméstico da organização social para incrementar, de forma crescente, a produtividade", e complementa que "ao contrário da lógica empresarial, cuja lucratividade e competitividade são os verdadeiros determinantes do crescimento da produtividade (...), no caso das regiões, é a produtividade que se transforma no verdadeiro e principal determinante da competitividade". Para Pike, Rodrìguez-Pose e Tomaney (2010) o desenvolvimento deve possuir um escopo amplo e incluir aspectos econômicos e preocupações sociais, ambientais, políticas e culturais. As abordagens devem englobar o desenvolvimento territorial integrado, com foco na mobilização de recursos locais e vantagens competitivas pertencentes e gerenciadas localmente. Para os autores

Definitions are socially determined in the context of historically enduring themes, principles and values, incorporating geographical diversity and changes over time. The historical evolution of 'development' in the postwar period emphasises its changing meanings, geographical differentiation, broadened focus and approaches to local and regional development. Geography matters as a causal factor in local and regional development. Territories evolve as defined áreas in which particular definitions of local and regional development are constructed and 
pursued. Places shape the geographical diversity and unevenness of local and regional development. Economic, social, political, environmental and cultural processes influence local and regional development across, between and through different scales p. 56).

Como os princípios e valores sociais podem diferir geograficamente é necessário conhecer as diferenças e desigualdades sociais e geográficas para uma melhor compreensão da distribuição de onde e quem se beneficia ou perde com formas específicas de desenvolvimento regional, particularizando os objetos, sujeitos e aspectos de bem-estar social das comunidades locais e o seu desenvolvimento. Para Boisier (1995, p.53),

El concepto de desarrollo debe ser ciertamente entendido como un concepto multidimensional y dinámico. Se refiere a cambios (cuya dirección y velocidad constituyen puntos controversiales) en los planos: económico, político, social, ambiental, tecnológico y territorial y por lo tanto se asocia a procesos y cuestiones tales como el crecimiento de la producción, el progreso técnico, la distribución del poder, la distribución del ingreso, la distribución de oportunidades individuales y colectivas, la preservación de los recursos y del medio ambiente en general, y la organización territorial de la sociedade.

O desenvolvimento de um determinado território envolve, segundo Pedrana (2013) estratégias e questões diferenciadas e, prioritariamente, um relacionamento profícuo entre os setores público e privado. Portanto, segundo Vázquez-Barquero (1999), para utilizar o capital humano, infraestrutura ou inovação de forma otimizada, as políticas de desenvolvimento necessitam estar alinhadas com os limites e o potencial das instituições locais e, complementarmente, North (1990) afirma que é importante que haja uma estrutura institucionalizada com regras e normas que garantam uma governança adequada para o território.

As experiências territoriais vivenciadas nos países industrializados da Europa, sob condições específicas também podem ser desenvolvidas em outros locais, como em países Africanos e Latinos, pois a partir das transformações advindas com a globalização, a pertinência das práticas territorializadas se tornaram uma oportunidade para que os municípios, regiões, ou mesmo países não ficassem totalmente submetidos e dependentes de ajudas internacionais, de mercadorias padronizadas de consumo, ou mesmo vulneráveis a concorrência de grandes redes internacionais de produtos (PECQUEUR, 2005).

Considerando a abordagem territorial de desenvolvimento, as identidades servem como diretrizes para os processos operacionais de reconhecimento e valorização de recursos culturais específicos, os quais os atores locais se apropriam com a intenção de legitimar uma identidade perante o próprio grupo e os demais. Com isso, a identidade vinculada ao território a partir de construções identitárias decorrentes das dinâmicas sociais, culturais, ambientais ou outras que os atores locais elegem como "suas" são os elementos fundamentais para que a perspectiva territorial tenha flexibilidade para acionar no território, diferentes recursos e valores em nome do desenvolvimento. Foi o caso do território conhecido como Quarta Colônia, pois diante de sua identidade étnica-cultural foi possível articular a atividade de turismo como estratégia para que seus atores pudessem encontrar alternativas locais de desenvolvimento.

A operacionalização das atividades ligadas ao turismo, neste contexto de território, requer uma governança que proporcione a confiança, que segundo Baldi 
e Lopes (2004), se configura no elemento capaz de desenvolver o sentimento de reciprocidade entre os parceiros da cadeia produtiva. Considerando que governança para Nordin e Svensson, (2006) está relacionada com a auto-organização de atores que possuem interdependência em suas atividades, que trocam recursos e que possuem regras compartilhadas que delimitam a permissão ou impedimento de ações, e, para Humphrey e Schmitz (2001, p. 06) "se refere a relações entre empresas e a mecanismos institucionais através dos quais se consegue a coordenação extramercado das atividades dentro de uma cadeia", se torna compreensível que nas atividades do setor de turismo a governança seja relevante. Ainda, segundo o Ministério do Turismo (Brasil, 2007, p.16), "essa capacidade de governar pressupõe uma administração participativa que envolve as populações locais na elaboração, monitoramento e, em alguns casos, na execução de políticas públicas". Porém, as peculiaridades do setor de turismo, que congrega múltiplos atores, proporciona entraves que necessitam de medidas específicas de governança aplicadas ao setor. Para Costa e Toni (2007, p. 14)

uma efetiva governança tem, portanto que trabalhar com os limites naturais dos destinos e dos roteiros, contabilizar os efeitos sinérgicos da ocupação de várias localidades encadeadas, desenhar regras de interação, monitorar e punir os desrespeitos. Dessa forma seriam potencializados ganhos de competitividade para as aglomerações produtivas do turismo e para seus empreendedores de pequeno porte, que lá deverão permanecer em longo prazo e por isso, necessitam de recursos preservados que permaneçam como produtos turísticos diferenciados para o mercado.

Complementarmente, de acordo com o Ministério do Turismo, o modelo de governança de regiões turísticas "deve ser elaborado a partir das práticas, experimentações e aprendizagens realizadas, que incluem participação, tomada de decisão e gestão coordenada e compartilhada" (Brasil, 2007, p.18), ou seja, pressupõe a participação de todos, com princípios de descentralização e integração regional.

\section{0 território Quarta Colônia e as expectativas em torno do turismo}

Diante das oportunidades promovidas pela globalização que acenou para as especificidades identitárias locais e distintivas do desenvolvimento territorial, tangenciadas pelas dinâmicas socioculturais e ambientais encontradas nos próprios territórios, a Quarta Colônia despertou como um território estratégico para as propostas de desenvolvimento territorial no Estado do Rio Grande do Sul na década de 1990.

O contexto sócio-histórico do território que hoje constitui a Quarta Colônia resultou da criação das colônias alemãs e italianas pelo governo imperial no final do século XIX com o objetivo de ocupar terras devolutas (desabitadas) e fazê-las produzir, assim como acontecia com as demais áreas das terras disponíveis no Brasil em meio às crises na Europa. Além de fatores econômicos e políticos das transformações do capitalismo, a Itália incentivava a vinda de imigrantes para o Brasil numa utopia libertadora na América, vista como um mundo de liberdade, alimento, trabalho e terra, diferentemente dos retratos da Itália em crise, opressora de padrões e rígidas regras, impostos, disputas religiosas e sua recente unificação (ZANINI, 2006). 
Inicialmente chegaram os imigrantes alemães em 1824 para formar as Colônias de São Leopoldo, de Santa Cruz e a de Santo Ângelo, e após 1850, os imigrantes italianos constituiriam os núcleos de Caxias do Sul, Conde d'Eu (atual Garibaldi), Dona Isabel (hoje Bento Gonçalves) e Cittá Nuova (Silveira Martins), a qual daria origem a Quarta Colônia Imperial de Imigração Italiana no ano de 1876 (FROEHLICH; VENDRUSCOLO, 2012). No entanto, o desmembramento da Colônia nos municípios de Júlio de Castilhos, Santa Maria e Cachoeira do Sul levariam a disputas e descontentamento políticos entre os imigrantes, que em diversas tentativas, fracassaram na busca por reagrupar o território e também propor outras novas divisões (SANTIN, 1986).

A partir dos anos de 1950 as tentativas isoladas de emancipação originariam diversos pequenos municípios emancipados, muitos remanescentes das terras loteadas pelo governo no século XIX e da região que originou a Quarta Colônia de Imigração Italiana (FROEHLICH; VENDRUSCOLO, 2012). Na década de 1970, localidades com descendentes de imigrantes italianos passaram por uma nova etapa, onde a identidade cultural italiana seria considerada algo positivo entre seus descendentes, acionados diante das comemorações do centenário da Imigração Italiana no Rio Grande do Sul no ano 1975.

Nos anos 90 o cenário econômico e político internacional reivindicou o acionamento de aspectos ambientais, culturais e sociais entre as projeções dos municípios e regiões tanto no Brasil como no exterior para encontrar alternativas sustentáveis de desenvolvimento nos territórios (CAZELLA, 2012). Na Quarta Colônia, algumas oportunidades para o desenvolvimento com vínculos territoriais puderam ser identificadas. As projeções do sentido territorial surgiram das oportunidades socioambientais e econômicas do programa de cooperação científica internacional Man and Biosphere (Mab) para reconhecimento de áreas remanescentes da Mata Atlântica como Reserva da Biosfera nos anos de 1991 e 1992. O Mab foi proposto pela Organização das Nações Unidas para a Educação, a Ciência e a Cultura (Unesco) e o Banco Mundial em parceria com o governo brasileiro (FROEHLICH; ALVES, 2007).

Com foco ambiental, o Programa Mata Atlântica na década de 1990, conseguiu implantar a Reserva da Biosfera da Mata Atlântica (RBMA) no Rio Grande do Sul, priorizando a conservação da biodiversidade, o desenvolvimento sustentável e o conhecimento tradicional e científico. A partir destas três prioridades, em 1994, a Unesco reconheceu o tombamento da Mata Atlântica no Estado e a criação da Reserva da Biosfera da Mata Atlântica. As áreas prioritárias escolhidas no Estado foram o Litoral Norte, a Quarta Colônia (Centro) e o entorno da Lagoa do Peixe na região sul do Estado (RIO GRANDE DO SUL, 2016).

A intenção era coibir a deteriorização sistemática de ecossistemas e recursos naturais singulares mediante o reconhecimento das áreas protegidas como Reservas da Biosfera das quais a Quarta Colônia foi contemplada através do Programa de Desenvolvimento Sustentável da Quarta Colônia (Prodesus) que constituiu em consórcio, nove municípios-membros para desenvolver programas e projetos de interesses regionais (FROEHLICH; ALVES, 2007).

O marco referencial e institucional do Programa Prodesus se deu no ano de 1996 mediante a criação do Consórcio de Desenvolvimento Sustentável da Quarta Colônia (Condesus) e seus nove municípios-membros. O Condesus é uma entidade 
de personalidade jurídica de Direito Privado, sem fins lucrativos que busca promover os interesses de seus municípios-membros, a partir de inciativas de planejamento, captação e execução, por meio de parcerias, de ações, projetos e programas de desenvolvimento sustentável da Quarta Colônia (SILVEIRA et al., 2012).

A intenção de integrar politicamente os municípios foi para superar as delimitações políticas-administrativas de um longo processo de colonização e com isso construir socialmente ideais em nome de um desenvolvimento territorial. $O$ Consórcio foi e continua sendo a principal ação política de articulação na Quarta Colônia (FROEHLICH; VENDRUSCOLO, 2012). As estratégias articuladas serviram para fornecer identidade distintiva ao território e priorizar atividades que valorizassem os recursos específicos e impulsionassem os projetos de desenvolvimento no sentido territorial, requisitando a atividade de turismo como principal dispositivo para tais projeções.

Entre as ações do projeto inicial Prodesus estavam atividades envolvendo desde a base social de construção do território; atores locais em projetos de formação em Educação Ambiental e Patrimonial; o resgate da memória cultural dos imigrantes italianos; inovação de técnicas e práticas de diversificação e reconversão produtiva para a agricultura ecológica e sustentável, bem como, a discussão e implantação de atividades ligadas ao turismo rural, cultural e ecológico na região (FROEHLICH; ALVES, 2007).

Desde os anos de 2000, a aposta na promoção do turismo rural passou a ser percebida como uma estratégia fundamental para recuperar e conservar a originalidade natural e cultural local e pontualmente o Prodesus pode articular a animação da região diante das potencialidades que seriam buscadas por turistas (DIESEL et al., 2012).

As primeiras iniciativas do Condesus deram conta de formatar roteiros turísticos integrados; reunir e informar as comunidades para a atividade de turismo; formar condutores de turismo local e guias de turismo regional; realizar a sinalização turística nos atrativos e elaborar materiais de divulgação (folders e cartões-postais) para a divulgação da Quarta Colônia e comercialização dos roteiros (FROEHLICH; ALVES, 2007).

Nos roteiros e materiais de divulgação usados na Quarta Colônia, os recursos mobilizados referenciavam aspectos ambientais, a biodiversidade da Mata Atlântica e o relevo acidentado do território que em diversos cenários despontavam em cascatas e quedas d'água. Nos recursos culturais, a etnicidade e a cultura local apareciam em meio a religiosidade herdada dos imigrantes italianos, hoje visualizados nas diversas igrejas, capiteis, sinos, capelas e na arquitetura colonial do modo de vida dos colonizadores. Entre os hábitos e costumes, a gastronomia apare em destaque nos almoços típicos italianos durante as festividades locais (FROEHLICH; ALVES, 2007).

Dos recursos divulgados pelo Condesus, muitos aspectos culturais passaram a ser reconhecidos pelos atores locais como elementos identitário, distintivo e estrategicamente atrativos. Estes recursos constituem o cotidiano das práticas religiosas, da vivência local, da paisagem arquitetônica, dos hábitos alimentares e produtivos do território e passaram a ser requisitados como bens culturais e 
símbolos de uma cultura diferenciada condicionada no acionamento promovido exclusivamente pelo Consórcio.

No entanto, ao mesmo tempo em que houve significativa ativação dos recursos locais por parte das iniciativas do Condesus, estimulando a criação de empreendimentos e de projetos para a comercialização do turismo, as dificuldades não demoraram a surgir. Tão logo iniciaram a divulgação do território, a falta de apoio público efetivo junto aos empreendedores locais, a capacitação não continuada, a falta de capacitação técnica dos atores locais, incluindo gestores municipais para enfrentar a sazonalidade característica do setor, entre outras medidas equivocadas que criaram cerca de dezoito roteiros integrados em um território em proximidade acabaram negligenciando os efeitos da atividade rapidamente.

Atualmente, as práticas em torno do turismo acontecem independente do apoio do Condesus e mesmo que a entidade usufrua de narrativas incentivadoras da atividade turística, quase não são visualizados interesses em atender suas propostas de desenvolvimento sustentável do turismo. Outras ações por parte do Condesus seguem acontecendo e captando projetos em torno de interesses administrativos das municipalidades, mas em termos de turismo, ainda estão fragilizadas.

\section{Resultados}

Assim como Souza (1997) faz referência a uma necessidade de concertação social junto aos territórios quando se articula uma perspectiva territorial, Froehlich e Vendruscolo (2012) também apresentam a experiência da Quarta Colônia, que na busca de uma identidade territorial teve com o Condesus a base para articular seus recursos e projetar o território para o desenvolvimento. Na Quarta Colônia o Condesus representa uma instância de governança, que embora de forma parcial, inclui a participação, tomada de decisão e gestão coordenada e compartilhada de muitos atores ligados ao turismo na região, tal como é definida pelo Ministério do Turismo no documento denominado Institucionalização da Instância de Governança Regional (BRASIL, 2007). Desde então, a narrativa de construção identitária da Quarta Colônia usufrui dos sentidos acionados pelo passado, rememorando a trajetória de ocupação, o modo de vida dos imigrantes, a cultura étnica, religiosa e social, a culinária local, as manifestações culturais, a paisagem cênica, enfim. São diferentes elementos acionados pelas narrativas identitárias que se tornaram símbolos e, na medida que surgem na memória dos atores, constituem-se de significados reconstruídos e reconhecidos pelos grupos que os acionaram (FROEHLICH; VENDRUSCOLO, 2012).

No entanto, o estudo apontou que apesar do apoio governamental, a comunidade local não esteve inserida no processo de desenvolvimento do turismo, e a fragilidade do capital social impediu que muitas atividades turísticas obtivessem êxito ao longo dos anos. Apesar do fluxo turístico ainda ser considerado pontual, sem continuidade para um desenvolvimento efetivo do fenômeno, o crescente número de visitantes é visualizado em diversas atrações culturais, especialmente as festividades que acontecem nas localidades do interior das pequenas sedes dos municípios. Por outro lado, a visita aos atrativos locais é concentrada nos finais de 
semana, e muitas vezes, esbarram em pontos fechados para visitação ou mesmo com precária infraestrutura receptiva.

Para Silva (2014), esses fatos representam a falta de políticas públicas com ações efetivas dos gestores municipais para promoção do turismo, limitando a permanência dos visitantes nos municípios. Por isso, os eventos e as festividades aparecem como possibilidade estratégica para atrair visitantes e consumidores no território em outras modalidades que não vinculadas aos roteiros turísticos incentivados pelo Condesus e outras entidades público-privadas.

No estudo de Silva (2014), os roteiros turísticos propostos pelo Serviço Brasileiro de Apoio às micro e pequenas empresas (Sebrae) em convênio com o Condesus no ano de 2002 buscaram mapear os mais significativos atrativos para atrair visitantes, porém os proprietários não conseguiram autonomia e a maioria não obteve o êxito esperado. Ao longo dos anos, outras iniciativas surgiram, a exemplo da Rota Turística e Gastronômica Santa Maria - Silveira Martins, criada em 2008, mas que ainda passam por ajustes. Para Silva (2014), apesar dos avanços pontuais em temos de estudos e pesquisas houveram recorrentes retrocessos nas ações de projetos e programas, em especial aquelas que demandaram um trabalho coletivo e a expressão da cooperação entre os diversos atores envolvidos com o turismo na microrregião da Quarta Colônia, o que pode estar atrelado ao capital social do território.

Atualmente, o turismo tem sido visualizado no território como um dos principais dispositivos utilizados na estratégia de divulgação e consumo dos recursos locais. Como sinais identitários, potencializadores e distintivos das festividades contemporâneas, os elementos culturais aparecem constituídos pela gastronomia local, a religiosidade e a cultura italiana. Estes elementos simbólicos são usados como atrativos turísticos na projeção da construção identitária do local, na afirmação étnica, nos dispositivos de consumo, na reafirmação e difusão espetacularizada de mitos, no acionamento simbólico para o comércio, no cenário comunicativo midiatizado e espetacularizado para atrair visitantes (FROEHLICH, 2002; GUIMARÃES, 2011).

A atividade turística funciona de forma pontual, sem o ativamento de agências receptivas locais. Muitos empreendimentos, como agroindústrias e restaurantes comercializam alimentos e pratos da cozinha típica, dispondo diferentes produtos junto a cesta de bens e serviços encontradas no território. Apesar dos roteiros terem feito parte de folders e folhetos de divulgação do Condesus nos anos 2000, desde então não funcionam satisfatoriamente na prática, relatam os proprietários de empreendimentos. Para muitos membros da comunidade, os restaurantes que atendem visitantes são caros e nem sempre revelam a cozinha típica, o que é visto como algo que não é a realidade local.

Ao invés de divulgar os roteiros e tentar reativá-los, os atores locais revelam que seguem ofertando produtos agroalimentares locais e oferendo os serviços costumeiramente existentes nas festividades, sem distinguir visitantes ou pessoas da própria comunidade. Para muitos, servir turistas ou amigos e parentes tem a mesma importância, pois muitas vezes, o bem servir como um dom entre os moradores, herdados desde a imigração e presentes entre os serviços de eventos festivos. Com os atrativos naturais, a paisagem revela locais bucólicos entre atividades rurais tais como as plantações de arroz, soja, batata e milho em contraste 
com a mata atlântica e a própria reserva da biosfera. As trilhas e caminhos rurais acontecem por grupos auto organizados e eventualmente as agencias receptivas realizam atividades. O Condesus busca superar os problemas encontrados com o capital social, ofertando novos projetos que incluem a paleontologia, no entanto efetivamente ainda não é comercializado e visualizado como parte da identidade territorial da Quarta Colônia por seus atores locais.

Por outro lado, como parte da composição do produto turístico, o setor de eventos cumpre a tarefa de induzir o movimento social na busca de produtos ofertados no território e disponíveis para o consumo turístico, tais sejam os diversos motivos de deslocamento acionados em busca de recursos e produtos vinculados a cultura, a religiosidade, a natureza, ao conhecimento, a recreação, as novidades tecnológicas ou para negócios ofertados entre os municípios. Nesse sentido, o turismo foi requisitado para ativar o setor de eventos como uma estratégia capaz de captar as diferentes motivações de viagem, aumentar o tempo de permanência do visitante no destino, minimizar a sazonalidade característica do setor turístico, bem como para valorizar o território com seus aspectos culturais e qualitativos de atratividade turística.

Entretanto, a atividade de turismo até o final de 2019 dava sinais de uma mudança de cenário, motivada pelo aumento visível de visitantes no território em busca de atividades turísticas. De certa forma, a valorização do território através das instâncias locais de liderança, a exemplo do CONDESUS, atuando em conjunto com os demais atores locais foram os principais responsáveis por esta mudança.

\section{Aspectos conclusivos}

No território Quarta Colônia, o turismo tem retomado seu processo de crescimento graças as atividades promovidas pelos atores locais que de forma conjunta, preparam e ao mesmo tempo, vivenciam atividades recreativas, trilhas e caminhos rurais, festejos e eventos gastronômicos de forma auto independente de programas e projetos oficiais de apoio e diretriz governamental. Mesmo o turismo ter sido uma das apostas para o desenvolvimento sustentável do território, a gestão pública pouco efetiva na área e a própria fragilidade do capital social identificados por Silva (2014) foram alguns dos principais elementos que desencadearam um enfraquecimento no desenvolvimento do turismo junto aos municípios. Apesar dos incentivos à persistência nos projetos locais de desenvolvimento e as tentativas das governanças institucionalizadas, muitos roteiros não conseguiram êxito e acabaram prejudicando também os empreendimentos agroalimentares e restaurantes típicos locais. Nesse escopo ressalta-se a pertinência e a relevância do relacionamento adequado e positivo entre os setores público e privado em prol do território que, segundo Pedrana (2013), é condição necessária para o desenvolvimento. Observando também a recomendação do Ministério do Turismo da necessidade de participação no Programa de Regionalização do governo federal, de modo que a articulação seja horizontalizada entre as municipalidades. Estas, integradas, a exemplo do que se busca no Centro do Estado, no território Quarta Colônia poderão se mobilizar para as possibilidades que a regionalização permite, seja em termos de estruturação dos destinos, gestão ou mesmo a promoção do turismo (MTUR, 2020). 
Entretanto, as novas oportunidades em torno da atividade turística vem acontecendo de forma auto organizada, onde os atores locais ativaram por iniciativas próprias os recursos locais que melhor serviam a sua realidade, demonstrando que por mais bem intencionado que foram as políticas públicas em torno de projetos de rotas e roteiros turísticos integrados, se a comunidade local não reconhecer as atividades turísticas como parte estratégica daquilo que consideram como novas oportunidades, o turismo não será uma atividade rejuvenescedora do território. Tanto que, na Quarta Colônia, o turismo segue pontual e independente dos incentivos governamentais, sendo o aspecto territorial um fator determinante para revelar os acontecimentos que dele emanam, confirmando a perspectiva de Vázquez-Barquero (1999) que enfatiza a importância da contribuição dos recursos humanos locais. À medida que a comunidade está integrada e envolvida com a preparação, a organização e a execução de eventos, novas ações e projetos de desenvolvimento local e regional podem ser projetados diante de uma perspectiva territorial, o que de fato não aconteceu na Quarta Colônia. Contudo, as iniciativas para o turismo no território, cuja base agrícola é predominante, encontrou no conteúdo cultural identitário as bases necessárias para evidenciar que toda e qualquer iniciativa de desenvolvimento depende do capital social que o reconhece, reivindica e chancela para usufruto de sua realidade. Neste escopo, ressalta-se a importância de concretizar e desenvolver a governança para aprimorar o sentimento de reciprocidade entre os parceiros e assegurar o desenvolvimento de elos consistentes entre os membros da cadeia produtiva do setor de turismo da Quarta Colônia.

Os aspectos evidenciados no estudo sobre o território da Quarta Colônia corroboram as afirmações de autores como Becker (2002), Boisier (1995), Pike, Rodrìguez-Pose e Tomaney (2010), Pedrana (2013), Vázquez-Barquero (1999) e North (1990), entre outros, que ressaltam a importância do desenvolvimento territorial integrado, com conhecimento e alinhamento da potencialidade das instituições locais, utilização adequada dos recursos (humanos e de infraestrutura) e a necessidade de mudanças em diferentes níveis (econômico, político, social, ambiental, tecnológico e territorial) que contribuam de forma harmoniosa e equilibrada na preservação e otimização dos recursos do território.

\section{REFERÊNCIAS}

ABRAMOVAY, R. Subsídios e multifuncionalidade na política agrícola europeia. Economia Rural, v. 40, n. 2, p. 235-264, 2002.

BALDI, M.; LOPES, F. D. Laços sociais e formação de arranjos organizacionais cooperativos - proposição de um modelo de análise. In: II SIMGEN - Simpósio de Gestão e Estratégia em Negócios. Rio de Janeiro, UFRural, 2004.

BECKER, D. F. A economia política do (des)envolvimento regional contemporâneo. Redes, v. 7, n. 3, p. 35-39, 2002. 
BERGER, P. L.; Luckmann, T. A construção social da realidade. 36. ed. Rio de Janeiro: Vozes, 2014.

BOISIER, S. Centralización y descentralización territorial en el proceso decisorio del sector público. Santiago de Chile: ILPES/CEPAL, 1995.

BRASIL. Ministério do Turismo. Coordenação Geral de Regionalização. Programa de Regionalização do Turismo - Roteiros do Brasil: Módulo Operacional 3: Institucionalização da Instância de Governança Regional / Ministério do Turismo. Secretaria Nacional de Políticas de Turismo. Departamento de Estruturação, Articulação e Ordenamento Turístico. Coordenação Geral de Regionalização. Brasília, 2007.

CAZELLA, A. A.; BURIGO, F. L. 0 desenvolvimento territorial no Planalto Catarinense: o difícil caminho da intersetorialidade. Revista Extensão Rural, n. 15, p. 5-30, 2008.

CAZELLA, A. A. As bases sociopolíticas do desenvolvimento territorial: uma análise a partir da experiência francesa. In: FROEHLICH, J. M. (Org.) Desenvolvimento territorial: produção, identidade e consumo. ljuí: Unijuí, 2012, p. 15-52.

COSTA, H. A.; TONI, F. Desafios para governança em destinos turísticos e roteiros integrados. ANPTUR. IV Seminário da Associação Brasileira de Pesquisa e Pós Graduação em Turismo UAM, 2007.

DIESEL, V. et al. As agroindústrias familiares da Quarta Colônia: a difícil escolha entre tradição e modernidade. In: FROEHLICH, J. M. (Org.). Desenvolvimento Territorial: produção, identidade e consumo. Ijuí: Unijuí, 2012, p. 385-419.

FROEHLICH, J. M. Rural e natureza: a construção social do rural contemporâneo na região central do Rio Grande do Sul. Tese (Doutorado), Universidade Federal Rural do Rio de Janeiro, Rio de Janeiro, RJ, 2002.

FROEHLICH, J. M.; ALVES, H. F. I. Novas identidades, novos territórios: Mobilizando os recursos culturais para o desenvolvimento territorial. Extensão Rural, n. 14, p. 6590, 2007.

FROEHLICH, J. M.; VENDRUSCOLO, R. A construção social da identidade territorial Quarta Colônia: tramas e sentidos da narrativa. In: FROEHLICH, J. M. Desenvolvimento Territorial: Produção, Identidade e Consumo. ljuí: Unijuí, 2012.

GUIMARÃES, G. M. Racionalidades identitárias na produção e comercialização de alimentos coloniais na Quarta Colônia - RS. Tese (Doutorado). Universidade Federal do Rio Grande do Sul, Porto Alegre, RS, 2011.

HUMPHREY, J.; SCHMITZ, H. A governança em cadeias globais de valor. 2001. Disponível em: <http://www.nead.gov.br/artigodomes>. Acesso em: 15 abr. 2020. 
MANFIO, V.; BENADUCE, G. M. C. Quarta Colônia de Imigração Italiana/RS: uma abordagem sobre a cultura e identidade. Geosul, v. 32, n. 65, p. 260-273, 2017.

MINISTERIO DO TURISMO - MTUR. Programa de regionalização do turismo. Brasília, DF $\quad$ Mtur, 2020. Disponível em: http://www.regionalizacao.turismo.gov.br/index.php?option=com_content\&view=a rticle\&id=77\&ltemid=107. Acesso em: 17 abr. 2020.

NORDIN, S.; SVENSSON, B. The Significance of Governance in Innovative Tourism Destinations. In: 55th AIEST Congress Brainerd, USA, 2005. Disponível em: www.etour.se. Acesso em: 15 abr. 2020.

NORTH, D. Institutions, Institutional Change and Economic Performance. Cambridge: Cambridge University Press, 1990.

$P$

PECQUEUR, B. O desenvolvimento territorial: uma nova abordagem dos processos de desenvolvimento para as economias do Sul. Raízes, v. 24, n. 01 e 02, p. 10-22, 2005.

PEDRANA, M. Local economic development policies and tourism: An approach to sustainability and culture. Regional Science Inquiry Journal, v. 1, p. 91-99, 2013.

PIKE, A.; RODRIGUEZ-POSE, A.; TOMANEY, J. Local and Regional Development. London: Routledge, 2010.

RIO GRANDE DO SUL. Projeto RS Biodiversidade. Porto Alegre. 2016. Disponível em: http://www.sdr.rs.gov.br/portal. Acesso em: 10 set. 2019.

SANTIN, S. A imigração esquecida. Porto Alegre: Editora EST, 1986.

SCHNEIDER, S. A abordagem territorial do desenvolvimento rural e suas articulações externas. Revista Sociologias, v. 6, n. 11, p. 88-125, 2004.

SILVA, A. P. Turismo e desenvolvimento territorial na Quarta Colônia-RS/Brasil: uma abordagem na perspectiva do capital social. Tese (Doutorado). Universidade Federal de Santa Maria, Santa Maria, RS, 2014.

SILVEIRA, P. C. et al. Identidades socioculturais e sistemas agroalimentares localizados: o percurso da Quarta Colônia, RS-Brasil. In: FROEHLICH, J. M. (Org.) Desenvolvimento territorial: produção, identidade e consumo. ljuí: Unijuí, p. 353383, 2012.

SOUZA, M. L. Algumas notas sobre a importância do espaço para o desenvolvimento social. Território: Garamond, p. 15-35, 1997. 
TRIVIÑOS, A. N. S. Introdução à pesquisa em ciências sociais: a pesquisa qualitativa em educação - o Positivismo, a Fenomenologia, o Marxismo. São Paulo: Atlas S. A. 2011.

VÁZQUEZ-BARQUERO, A. Desarrollo, redes e innovación: lecciones sobre desarrollo endógeno. Madrid: Piramide, 1999.

VEIGA, J. E. O Brasil rural ainda não encontrou seu eixo de desenvolvimento. Estudos Avançados, v. 15, n. 43, p. 101-119, 2001.

ZANINI, M. C. C. Italianidade no Brasil Meridional: a construção da identidade étnica na região de Santa Maria - RS. Santa Maria: UFSM, 2006.

Caroline Ciliane Ceretta. Graduação em Administração - UNIVATES, Graduação em Turismo - UNISC, Mestrado em Turismo - UCS, Doutorado em Extensão Rural - UFSM. Professora Adjunta da Universidade Federal de Pelotas. carolineceretta@hotmail.com

Dalva Maria Righi Dotto. Graduada em Administração - UFSM, Mestra em Desenvolvimento Regional - UNISC, Doutora em Desenvolvimento Regional UNISC, Pós doutorado em Administração - UFRGS. Professora Adjunta da Universidade Federal de Santa Maria.dalvadotto@gmail.com

Mônica Elisa Dias Pons. Graduação em Comunicação Social - UFSM

Mestrado em Comunicação Social - PUCRS, Doutorado em Comunicação Social PUCRS, Pós doutorado Comunicação Social - UFRGS. Professora Adjunta da Universidade Federal de Santa Maria.monica@ufsm.br

Nome Sobrenome letra candara tam 11 negrito. Greicy Sofia Maysonnave Doutoranda em Zootecnia - Universidade Federal de Santa Maria, Graduada em Zootecnia - UFSM, Graduada em Licenciatura Plena - UFSM, Mestrado em Zootecnia - UFSM.greicysm@gmail.com

Como citar: CERETTA, Caroline Ciliane et al. Perspectivas territoriais de desenvolvimento a partir do Turismo Rural: o caso do território Quarta Colônia/RS, Brasil. Redes (St. Cruz Sul, Online), Santa Cruz do Sul, v. 25, p. 2343-2360, 2020. ISSN 1982-6745. doi:https://doi.org/10.17058/redes.v25i0.14544. 
Perspectivas territoriais de desenvolvimento a partir do Turismo Rural: o caso do território Quarta Colônia/RS, Brasil

\section{CONTRIBUIÇÃO DE CADA AUTOR}

a. Fundamentação teórico-conceitual e problematização: Caroline Ciliane Ceretta, Dalva Maria Righi Dotto e Monica Elisa Dias Pons

b. Pesquisa de dados e análise estatística: Caroline Ciliane Ceretta

c. Elaboração de figuras e tabelas: não se aplica

d. Fotos: não se aplica

e. Elaboração e redação do texto: Caroline Ciliane Ceretta, Dalva Maria Righi Dotto, Monica Elisa Dias Pons e Greicy Sofia Maysonnave

f. Seleção das referências bibliográficas: Caroline Ciliane Ceretta, Dalva Maria Righi Dotto e Monica Elisa Dias Pons

Fontes de financiamento: não se aplica. 